\title{
COMPARISON BETWEEN SPOT AND LANDSAT IMAGERY OF RUTFORD ICE STREAM, ANTARCTICA
}

\author{
(Abstract) \\ by \\ D.G. Vaughan and C.S.M. Doake
}

(British Antarctic Survey, Natural Environment Research Council, High Cross, Madingley Road, Cambridge CB3 0ET, England, U.K.)

\begin{abstract}
A SPOT image of Rutford Ice Stream taken on 8 January 1987, when compared with a Landsat image of 3 February 1974, shows that surface topographic patterns have been displaced down-stream by several kilometres. Ice velocities derived from these measurements agree with those made during limited ground-based surveys in the near vicinity. Earlier interpretation of the surface topography, based on the character of airborne radio echo-sounding records and the relationship between ice thickness and surface elevation (Doake and others, 1987), suggested that there was partial grounding of the glacier sole. If this interpretation is correct, one implication is that the substrate to the ice stream is mobile and being transported at speeds comparable with that of the ice. As this seems unlikely, we are considering alternative explanations.

Radiance values from SPOT images have been compared with surface slopes measured along an optically
\end{abstract}

levelled line made during a ground-based survey in February 1987. There is a strong correlation between surface slope and radiance, suggesting that our goal of deriving quantitative topographic data from a single satellite image is attainable (Vaughan and others, 1988).

\section{REFERENCES}

Doake, C.S.M., R.M. Frolich, D.R. Mantripp, A.M. Smith, and D.G. Vaughan. 1987. Glaciological studies on Rutford Ice Stream, Antarctica. J. Geophys. Res., 92(B9), 8951-8960.

Vaughan, D.G., C.S.M. Doake, and D.R. Mantripp. 1988. Topography of an Antarctic ice stream. In SPOT 1 image utilization, assessment, results. Toulouse, CNES Cepadues-Editions, 167-174.

\section{THE UNDERSIDE OF ARCTIC SEA ICE IMAGED BY SIDESCAN SONAR}

\section{(Abstract)}

by

P. Wadhams

(Scott Polar Research Institute, University of Cambridge, Lensfield Road, Cambridge CB2 1ER, England, U.K.)

Despite extensive submarine operations in the Arctic, little is yet known about the three-dimensional morphology of the ice underside. Several studies have been done using upward-looking sonar, which yields a linear profile of ice draft from which the distributions of features such as pressure ridges and leads may be derived. Such a profile gives no information about the spatial morphology or appearance of the ice bottom surface. In contrast, the upper ice surface has been well documented from airborne and satellite-borne sensors such as synthetic aperture radar, passive microwave, infra-red, and visual imaging. Here I report the first extensive set of imagery of the underside of sea ice in the Arctic Ocean. Sidescan sonar images show a distinct difference between the appearance of first-year ice and of multi-year ice. First-year ice has a smooth bottom except for a network of cracks, while multi-year ice is covered with an array of blisters or bulges. The clear discrimination between ice types enables sidescan sonar to be used as a means of validating airborne passive microwave data.

The substance of this work has now been published in Nature (Wadhams, 1988).

\section{REFERENCE}

Wadhams, P. 1988. The underside of Arctic sea ice imaged by sidescan sonar. Nature, 333(6169), 161-164. 